\title{
Using Consumer Advertising and Promotional Marketing Materials for Historical Research: 1960s Heinz Baked Beans
}

\author{
Richard A. Hawkins
}

\begin{abstract}
This case study will equip you with the intellectual and practical toolkit necessary to investigate and derive worthwhile information from historical advertising and promotional marketing materials, using the example of a scrapbook of baked beans advertisements from the 1960s. Most of the print advertising from this period has survived in archives around the world in various formats, including the original publications, microfilmed copies, and more recently digitised scans. Not all the reproductions are high quality. Furthermore, while some of the original advertisements were published in colour, many have been reproduced in black and white. Advertising can reveal a lot more than just the product being advertised. The text and images used can reveal information about the advertising agency, the agency's client, the product being advertised, the consumers being targeted, and how the agency and its client view the society in which they are working. In this case study, you will learn what analytical questions you can ask of such sources and sample the kinds of answers you might expect to find in them. Analysis of the Heinz Baked Beans scrapbook also reveals information about how advertising campaigns, promotions, and competitions evolved during the period 1961-1968.
\end{abstract}

\section{Learning Outcomes}

After reading this case study, you will be able to:

- Contextualise mid-twentieth century British consumer advertising.

- Formulate questions that may be appropriately and usefully asked of advertisements.

- Derive data from selected advertisements to answer analytical research questions.

- Understand how advertisements can provide insights into their targeted audience.

\section{Initial Steps and Questions}

Before reading this piece and evaluating the primary source in full, you may want to reflect on these questions and initial steps:

1. What is the material nature of the source? What form of media is being used for the advertising?

2. Who created the advertisement?

3. Who commissioned the advertisement?

4. What product is being advertised? 
5. What period is the advertisement from?

\section{Contextual Information}

Advertising in Britain dates back to the Roman era. However, this case study focuses on advertisements placed in newspapers and magazines during the 1960s. Newspapers and magazines have their origins in the newsbooks which first emerged in Britain in the seventeenth century. The earliest surviving example of a newsbook advertisement is from $1622 .{ }^{1}$ During the nineteenth and twentieth centuries, processed food manufacturing companies made great use of newspapers and magazines to advertise their products. From the late nineteenth century, illustrated advertisements such as the ones featured in this case study became commonplace. From the 1920s, advertisers adopted an additional medium, commercial radio. Some of the print advertisements in this case study are linked to radio advertisements. In the early 1960s, the advertising industry was adjusting to the disruption caused by the introduction of a new form of advertising media during the previous decade, commercial television. Television advertising provided the opportunity to reinforce existing print and radio advertising campaigns as well as reach new audiences who had not engaged with traditional media. ${ }^{2}$

There are many reasons why advertisers advertise branded products. These include the reversal of declining sales, the need to increase sales following an increase in productive capacity, a response to competition from the producer of a complementary branded product to protect market share, and a response to competition from a substitute product. Advertisements provide us with valuable insight into society through the chosen themes; text and artwork were used to advertise the product. Advertisers sometimes seek to link their advertisements to contemporary popular culture or celebrities.

Historians have traditionally neglected advertising as an area of research. It is only relatively recently that a dedicated academic journal has been founded: the Journal of Historical Research in Marketing in 2009. However, a lot can be learnt from researching advertisements about economic and social change. The evolution of the form and function of advertisements can be linked to the development of markets for goods and services. They reflect the objectives of their creators. Advertisements utilise semantic choices and visual designs to market a product. The use of illustrations in billboard, magazine, and newspaper advertising from the second half of the nineteenth century gave rise to the profession of the commercial artist; their work, to repurpose the words of a British politician, has formed a 'poor person's art gallery'. However, apart from a 
notable exception - the Shell advertising campaign of the 1930s - the artists' names are mostly unacknowledged, reflecting a British upper-class prejudice against trade. Advertisements thus inform us about the habits and mores of the societies in which they are created. Sometimes, advertisements further an agenda beyond promotion. For example, during the Second World War, some British advertisers linked their products to the war effort, reinforcing government public information advertising.

\section{Source Analysis Questions}

Now we have addressed the initial questions (and taken the initial steps), we know the nature of the source and a little of the sociohistorical context. We are now going to conduct a more indepth analysis of this source. In analysing the advertisements, the questions you should address in your analysis include the following:

1. Why is the product being advertised?

2. What type of technique is the advertiser using?

3. Is the advertisement targeted at a particular age group?

4. Is the advertisement targeted at a specific socioeconomic group and/or gender?

5. How is the advertisement designed? How are the text and images laid out? How creative is the advertisement?

6. What kind of language is used in the advertising copy?

7. What other context-specific questions can this source provide insight into? For example, how far do the advertisements provide us with an insight into social class in midtwentieth century Britain?

\section{Critical Evaluation}

\section{Initial Questions: Identification of the Advertiser, the Client, Medium Used, and the Product Being Advertised}

We begin our evaluation by working through those initial questions. This case study is based on a series of advertisements for a convenience food - tinned baked beans - collected in a scrapbook. Therefore, we are working with a collection of advertisements rather than an individual advertisement. The scrapbook includes reference to advertisements which employed various 
forms of media including newspapers, magazines, radio, and television. The scrapbook is believed to have been created by the advertiser, a multinational food processing company - Heinz - as a record of the advertising undertaken on its behalf by the advertising agency, Young \& Rubicam. I contacted the original archive, the History of Advertising Trust, to establish this. They were able to confirm that Young \& Rubicam were employed by Heinz for the whole of the period, 1961-1968. Young \& Rubicam had held the Heinz account since 1948. We can infer the scrapbook was compiled by Heinz as the contemporary Young \& Rubicam guard books for Heinz were much larger, had the brand labelled on the outside, and included more detailed descriptions of media placings inside. Furthermore, the scrapbook is labelled as 'baked beans advertisements' rather than 'Heinz baked beans advertisements', which suggests it was already at Heinz and not at Young \& Rubicam. The advertised product is tinned baked beans, and the scrapbook contains advertisements and other material for the period of approximately seven years during the 1960s.

Having discerned this initial information, we must now turn to the question of why the product is being advertised.

\section{Why Is the Product Being Advertised?}

This is the most important step for the advertising historian. Without an answer to this question, you will not be able to assess the success or failure of an advertising campaign. The rationale for Heinz producing tinned food should be considered in terms of the sociohistorical context. The 1920s saw rising wages in the United States placing domestic servants beyond the reach of middle-class families for the first time. In response, middle-class homemakers sought to economise on labour in the home. Using convenience foods such as tinned baked beans was one of a variety of labour-saving strategies. In contrast, in Britain, middle-class families could still afford to employ domestic servants in the period between the two world wars. They also considered tinned food to be an inferior and undesirable substitute for fresh food. In Britain, tinned food was mostly consumed by working-class families who purchased it because it was cheap $^{3}$ rather than labour-saving. Thus, in Britain, tinned food was to be predominantly bought by working-class consumers unlike in the United States. This continued to be the case after the Second World War, notwithstanding the fact middle-class families could no longer afford to employ domestic servants. ${ }^{4}$

The Heinz advertising campaign of the 1960s had two main objectives. The first was to expand the market for baked beans because Heinz had recently invested $£ 7$ million in the construction of 
a new factory at Kitt Green near Wigan, Lancashire, to keep pace with the growing demand for its products. ${ }^{5}$ Opened in 1959, it was the largest food processing factory in the British Commonwealth. ${ }^{6}$ The second was a response to advertising by its competitors, Crosse \& Blackwell ${ }^{7}$ and H.P. Sauce, ${ }^{8}$ which were in a distant second and third place in the marketplace. However, after the acquisition of the former by the Swiss multinational, Nestlé, in 1960, Heinz began to face much stronger competition in the baked beans market. ${ }^{9}$ In the early 1960s, Heinz, Crosse \& Blackwell and H.P. each spent over $£ 100,000$ a year on sales promotion, with Heinz spending even more. The Financial Times noted that the massive advertising appropriations of Crosse \& Blackwell and H.P. had done little to reduce Heinz's dominant position in the British market. In 1964, it accounted for $63 \%$ of the British market and $71 \%$ of the Scottish market. ${ }^{10}$

\section{What Type of Techniques Is the Advertiser Using?}

Advertisers use a wide variety of techniques which include association: using images such as a cartoon character in the hope that you will transfer positive feelings about the image to the product; a call to action: for example, 'Buy today!' — this removes all doubt about the next step; humour: using advertisements that make you laugh can catch your attention and be memorable; hype: using words like 'amazing' and 'incredible' can make products appear really exciting; prizes and gifts: using a chance to win a prize or receive a gift to attract attention; price: announcing a discounted price can make a product more attractive; sense appeal: using images and sounds to appeal to your senses; special ingredients: promoting a special ingredient may make you think the product is superior to others; and endorsements: a celebrity endorsing the product can be convincing.

There are a wide variety of techniques represented in the scrapbook. These include, for example, endorsements. Advertisements based around celebrities have been commonplace in the United States since the 1920s. ${ }^{11}$ Young \& Rubicam made use of this type of advertising technique during the 1960s. The Jack Jackson record promotion is one example (see image 21). Another example is advertising based around Ann Packer, an English sprinter, hurdler and long jumper, who had won a gold medal in the 800 metres and a silver in the 400 metres at the 1964 Summer Olympic Games. Packer featured in several Heinz Baked Beans advertisements including the one on the second page of image 53. These advertisements anticipated the later dominant role of athletes in American celebrity endorsement focussed 
advertising in the period from 1975 onwards. ${ }^{12}$ Nonetheless, overall, the scrapbook suggests celebrity endorsements only played a minor role in the 1960s Heinz advertising. Perhaps, tinned baked beans did not have much appeal to potential celebrity endorsers.

\section{How Is the Advertisement Designed? How Are the Text and Images Laid Out? How Creative Is the Advertisement?}

The Heinz Baked Beans scrapbook includes a variety of different designs. The advertisements placed in newspapers during the early 1960s tend to layout the text and images (image 13, second page) following conventions that date back to the period between the two world wars. The colour advertisements placed in women's magazines (image 5, both pages) also use a layout that can be traced back to the interwar years too. However, the advertising mostly uses contemporary typefaces and illustration styles rather than those of earlier decades.

Stephan Schwarzkopf has suggested American owned advertising agencies in Britain such as Young \& Rubicam 'stifled creative freedom' and that during the 1960s new more creative British firms entered the industry. As already noted, the early advertising in the scrapbook does indeed appear to be very conventional. However, from October 1964, there was a major change in the content of advertisements Young \& Rubicam placed in women's magazines. From this point forward, the advertisements featured artistic colour photographs of the product. These advertisements show that, contrary to Schwarzkopf, Young \& Rubicam embraced the creativity of the 'new wave' British agencies. ${ }^{13}$ The example on image 54 features a plate of baked beans as a thought bubble of a working-class girl with pigtails pictured near the bottom of the page. There is a small tagline of explanatory text at the very bottom of the page. Further examples feature a photograph of a baked bean on a fork (image 64), a wooden spoon of baked beans photographed above a plate of buttered toast (image 65), a photograph of baked beans on a fork with dripping tomato sauce (image 67), a cropped square from a photograph of a plate of baked beans (image 68), and a photograph of a single baked bean on a plate with a tiny Union Jack flag with a miniature text informing the reader of the countries where the ingredients originated from (image 73). The use of more abstract photographs with a minimum of text reflects the minimalist approach to advertising that the American advertising agency, Doyle Dane Bernbach, had adopted for its ‘debunking campaign’ begun for Volkswagen earlier in 1959. ${ }^{14}$

\section{What Kind of Language Is Used in the Advertising Copy?}


Language is a key element of nearly all advertisements. Advertising agencies communicate information on behalf of their clients to influence attitudes and to affect behaviour using words, phrases, and sentences. Robert G. Wyckham et al. observed that American advertising agencies often break the commonly accepted rules of standard English in determining the language to be used in advertisements. ${ }^{15}$ The more conservative advertising industry in Britain was less inclined to use nonstandard English during the 1960s. The language used in the examples of Heinz advertising in the scrapbook generally does not deviate much from standard English. However, in late 1965, Young \& Rubicam created an advertising slogan 'Beanz Meanz Heinz' (image 80) which was radically at variance with the rules of standard English. Thomas J. Barratt, chairman of the A. and F. Pears soap manufacturing company, popularised the use of slogans in late nineteenth-century Britain and the United States. Pamela Walker Laird notes that 'Slogans had been used before, but most of them did not pique the fancy the way that Barratt's... did'. ${ }^{16}$ While some products have been associated with slogans over a long period of time, the evidence is not clear whether they have any significant influence on sales. Nevertheless, from its very beginning, the memorable Heinz advertising slogan was considered to be a great success. In the year following its creation, it was used in a campaign based on television and posters. Before beginning the campaign in 1966, Heinz for the first time in their sixty years of poster advertising conducted extensive awareness research, which showed that an overwhelming proportion of the people to whom the slogan was shown immediately identified it correctly (image 100). The slogan was still in use over fifty years later. It is now wrongly claimed that Maurice Drake created the slogan for Young \& Rubicam's Heinz account two years later in $1967 .{ }^{17}$

\section{Is the Advertisement Targeted at a Particular Age Group? What Does This Source Tell Us About Advertising Focussed on Children?}

Some of the advertisements in this scrapbook are directed at children, which allows us to raise the question 'What does this source tell us about advertising focussed on children?'. During the 1960s, advertisers such as Young \& Rubicam targeted children in order to induce them to persuade their parents to purchase various food products and items of confectionery. This is sometimes referred to as 'pester power'. The author of this case study remembers successfully influencing his mother's grocery and confectionery purchases numerous times in response to advertising targeted at children during his childhood in the 1960s. McDermott et al. suggest that 
the term 'pester power' is pejorative 'of advertisers and marketers who target children through their promotional strategies, prompting purchase requests that would otherwise go unmade, or would lack the intensity and repetition that pestering entails. At best, this may create gratuitous tension in child-parent relationships; at worst, it may lead to exasperated purchases of items against a parent's better judgment - including the food they consider unhealthy, but that the child insists on having'. ${ }^{18}$ One method used by advertisers in the 1960 s was competitions offering children desirable prizes. The advertisement on image 19 published in August 1962 is an example from a girls' magazine and features a competition to win one of 57 pirate treasure chests with a choice of gifts to the value of $£ 50$. Though redacted, the advertisement on the first page of image 22 listed the name and addresses of the winners of the competition - as a note in the metadata of the source explains. As in the case of the caravan competition, this enables a researcher to assess the social profile of the winners. A later competition, the Guinea Pig Competition in July and August 1964 (image 46 and the first page of image 61), offered 10,000 piggy banks with a twenty-one shilling postal order. While the competition was open to everyone, it was undoubtedly focused on children. ${ }^{19}$

Advertisers in the 1960s also sought to exploit children who belonged to the most popular youth organisations. Thus, the Camp Cooking Competition was launched in October 1963 to engage with children who were Scouts and Girl Guides (image 37, first page). It took place at the Scout and Guide Stand at the sixth annual Camping and Outdoor Life Exhibition held at the Kensington Olympia Exhibition Centre, 5-16 January $1964 .^{20}$

Advertisers in the 1960s also used free gift promotions to engage with children. During the summer of 1962, in association with the Camping Club of Great Britain and Ireland, Heinz offered children a free thirty-two-page Camping Book in exchange for three baked bean tin labels (second page of image 11). At the end of the year, a second free gift promotion drew upon the popularity of Hollywood 'Western' films featuring cowboys and Indians (Native Americans) during the 1960s (image 27). The promotion offered children free Campfire Puzzle Books full of pictures, puzzles, and 'Western lore' (second page of image 28). The puzzle book was advertised in full-page advertisements in all fourteen big circulation children's magazines together with display material distributed to grocery stores.

The advertising industry was self-regulated from 1962 by an Advertising Standards Authority (ASA). ${ }^{21}$ Its approach was 'light touch'. It was not until 1978, under pressure from Roy Hattersley, the Secretary of State for Prices and Consumer Protection, ${ }^{22}$ that it investigated 
advertising to children and the use of children in advertisements. ${ }^{23}$ However, although the ASA produced a study paper on tighter controls on advertising to children, the new Conservative government elected in 1979 and headed by Margaret Thatcher did not share the concerns of its predecessor, and thus no action was required. ${ }^{24}$ So it is worth considering whether the Heinz advertising focussed on children reflects well on the industry's selfregulation.

\section{Is the Advertisement Targeted at a Specific Gender? What Can This Source Tell Us About Advertising Targeted at Women in 1960s Britain?}

Women were a particular focus for the advertising of convenience food because they were the predominant purchasers of groceries during the 1960s. Thus, much of the advertising in this scrapbook was specifically targeted at women. Many of the advertisements were placed in women's magazines such as Woman, Woman's Realm, Woman's Own, and Woman's Mirror. Young \& Rubicam used women's magazine advertising to target 'housewives' (homemakers) with school-age children, a gendered stereotype. The advertisements mostly use images of school-age children, thus appealing to women in their role as mothers. Many of the magazine readers would have been working mothers, but that is not apparent from the advertisements. Both pages of image 5 are examples of advertisements placed between October 1961 and November 1962. They each feature a large colour photograph of a working-class child eating baked beans. Middle-class parents would have been surprised to learn from the advertising that baked beans were nutritious for growing children. Subsequent advertisements placed in women's magazines such as those on both pages of image 20 feature large full colour photographs of groups of children at play who do not appear to be as distinctively working class and could as easily be classified as middle class. One interesting question arising from the women's magazine advertising is why none of it appears to be specifically targeted at elderly women, although they formed a significant proportion of women's magazine readers and were potential baked beans consumers too.

\section{What Can This Source Tell Us About the Use of Nonprint Advertising During the 1960s?}

Some of the Heinz print advertising in the scrapbook was also linked to television and radio advertising. Television advertising was still relatively new. The Independent Television (ITV) 
network of regional commercial television stations funded by advertising had only started broadcasting in September 1955. Unlike in some neighbouring continental European countries, Britain's state radio and television broadcaster - the British Broadcasting Corporation - had a monopoly of radio broadcasting. Commercial radio funded by advertising was not permitted in Britain until 1973. However, Radio Luxembourg broadcast English language music and popular shows supported by British advertisers from continental Europe to Britain throughout this period. Advertisements were also aired on an illegal pirate radio station, Radio Caroline North, during the $1960 \mathrm{~s}^{25}$

Young \& Rubicam used radio on a number of occasions during the 1960s to reinforce the Heinz print advertising campaigns. For example, in September 1962, Heinz launched a promotion in the grocery press (image 21), where in return for three baked bean tin labels and two shillings and sixpence the consumer could acquire 'Songs for a Singin' Party', a 45 r.p.m. record of 16 of Jack Jackson's all-time favourite tunes. Jackson was a radio personality, English trumpeter, and bandleader popular during the British dance band era. The advertisement notes the promotion would be carried in the national popular press read by the working class and lower middle class together with the TV listing magazines and Hit Parade. It was also linked to a series of fiveminute features broadcast by Radio Luxembourg.

Young \& Rubicam also used television to reinforce the print advertising. There is material in the scrapbook which documents the use of television to advertise Heinz Baked Beans. For example, two advertisements in the trade journal, The Grocer, from September 1964 preview a television advertising campaign to be launched the following month. In the advertisements, David Nixon, a magician and television celebrity, would inform viewers that if they collected Heinz Baked Bean labels and mailed them to him, he would give them one shilling for every three and refund their postage (image 48, the first page of image 49, and images 50-52).

\section{How Far Does the Source Provide Us with an Insight into Social Class in Mid- Twentieth Century Britain?}

Britain's market for groceries is segmented in part by social class. Although baked beans had originally been advertised to middle- and upper-class consumers, in the 1960s, tinned food consumption was skewed heavily toward working class and lower middle-class consumers. In order to determine which social classes the advertisements are targeted at, we need to identify the publications in which they were placed because the readership of national newspapers in Britain 
is segmented by social class. The advertisement on image 4 placed in the grocery trade press in February 1962 provides us with this information. It informs grocers of the Heinz Baked Beans advertising campaign which combines television and print advertising. It shows the newspaper advertising is focussed on newspapers read by predominantly working-class readers, the Daily Mirror, the Daily Record, the Sunday Pictorial, and the Sunday Post together with all the television listing magazines. (Significantly during the period covered by the scrapbook Heinz did not place advertisements in national broadsheets such as The Times, the Daily Telegraph, the Manchester Guardian, the Sunday Times, and the Observer, which were read by the middle-class and upper-class.) The advertising was based around a competition which offered fifty-seven caravans as prizes. Advertisements were also placed in specialist caravan magazines. Caravans were used by lower middle-class and aspirational working-class people for holidays. The scrapbook contains an advertisement from the Competitors Journal listing the names and addresses of the competition winners (first page of image 17). In this digital copy, the personal data of competition winners have been redacted, but if you were viewing the original source in the archive, Google Maps could be used to analyse addresses and social status.

'HenryJohn Heinz', in National Cyclopadia ofAmerican Biography 26. 294-5. New York: James T. White \& Company, 1937.

\section{Conclusion}

This case study using the example of a Heinz Baked Beans advertising scrapbook provides an introduction to some of the key considerations when evaluating advertisements as source material. We have explored how advertising agencies advertise their clients' products, and how advertisements can be focussed on a particular age group or gender or social class. Through the source example, we have gained insight into advertising creativity during the 1960s, and how advertisers sought to incorporate a new media, television, into their campaigns. During the 'Swinging 1960s', the growth rate of national disposable income was 3.1\% per annum marking a period of prosperity. ${ }^{26}$ Some contemporary middle-class intellectuals disapproved of this additional income being spent on items such as tinned food. The literary critic John Carey observes that the poet John Betjeman, who was popular with Britain's middle class as an opinion former, deplored "the appetite of the masses for "...tinned beans", ${ }^{27}$ On the eve of the Second World War, Betjeman had imagined 'tinned beans' being metaphorically blown to 'smithereens'. ${ }^{28}$ The success of the advertising represented in this scrapbook in increasing the 
consumption of tinned beans by Britain's working class to an unprecedented level must have really irked him.

\section{Postevaluation Questions}

1. The Young \& Rubicam marketing is focused on working class and lower middle-class consumers. Why did Heinz decide not to try to market baked beans to the upper middleclass unlike in the 1920s when it advertised in broadsheets such as The Times?

2. Why is so much of the Heinz advertising focussed directly or indirectly on children? Does this raise ethical issues?

3. What do the advertisements tell us about British society during the 1960s?

\section{Further Research Considerations}

If you were to research this area further, you might consider the following questions and discussion points:

1. How might you find out how representative the Heinz Baked Beans advertising, promotions, and competitions was of the marketing of packaged processed foodstuffs in Britain during the 1960s?

2. To what extent is the marketing of Heinz Baked Beans in Britain influenced by campaigns carried out during the same period by the parent company in the United States? How might this be explored?

3. What does the advertising tell us about public health policy during the 1960s?

4. What other sources and types of information would be required in order to contextualize and interpret the data gathered with regard to the economic and social history of the 1960s?

5. The Baked Beans scrapbook does not include any information about why the client commissioned the agency to advertise its product; it does not include any market research reports, nor does it include any agency analysis of the success or failure of the advertising. How might such additional information be useful, and where might we find it?

\section{Further Resources}


Alberts, Robert C. The Good Provider: H.J. Heinz and His 57 Varieties. Boston: Houghton Mifflin Company, 1973.

Frank, Thomas. The Conquest of Cool: Business Culture, Counterculture, and the Rise of Hip Consumerism. Chicago and London: University of Chicago Press, 1998.

Hawkins, Richard A. "Marketing History in Britain: From the Ancient to Internet Eras." In The Routledge Companion to Marketing History, edited by D. G. Brian Jones and Mark Tadajewski, 315-32. London and New York: Routledge, 2016.

Koehn, Nancy F. "Henry Heinz and Brand Creation in the Late Nineteenth Century: Making Markets for Processed Food.” Business History Review 73, no. 3 (Autumn 1999): 349-93.

McCafferty, E. D. Henry J. Heinz: A Biography, New York: Bartlett Orr Press, 1923.*

Skrabec, Quentin R. Jr. H.J. Heinz: A Biography. Jefferson, NC: McFarland \& Company, 2009.* Vogler, Pen. Scoff: A History of Food and Class in Britain. London: Atlantic, 2020.

*Both of these books contain significant factual errors.

\section{Notes}

1. Nevett, Advertising in Britain, 7-9.

2. Nevett, Advertising in Britain, 15-40, 67-99, 184-90; Street, Crossing the Ether, 97-186.

3. Advertisement, Daily Mirror, November 21, 1922, 14.

4. Levenstein, Revolution at the Table, 152, 162-4; TNA, CO760/10, Empire Marketing Board, Marketing Committee, Food Product Committee, Draft Report by the Food Products Committee on the Malayan Canned Pineapple Industry London, November 12, 1931, 1-2.

5. “Expansion by H.J. Heinz,” Financial Times, June 26, 1957, 1.

6. "New Factory at Kitt Green for H.J. Heinz," Financial Times, May 23, 1959, 5.

7. "Bid for Crosse and Blackwell," Financial Times, December 9, 1959, 1.

8. "Big TV Campaign for H.P. Baked Beans," Financial Times, October 24, 1957, 11.

9. "Bean Beano," Financial Times, April 16, 1963, 8; "Nestle's C \& B Bid Successful," Financial Times, February 4, 1960, 1. 
10. “A Bright Future for Canned Vegetables,” Financial Times, August 11, 1964, 6.

11. Segrave, Endorsements in Advertising, 14-33.

12. Segrave, Endorsements, 126-45.

13. Schwarzkopf, "From Fordist to Creative Companies."

14. Frank, The Conquest of Cool, 62-3, 68, 238.

15. Wyckham et al., "The Language of Advertising," 47.

16. Laird, Advertising Progress, 54-5.

17. Gwynn, “Heinz marks 50 years of 'Beanz Meanz Heinz' with Dining Bus Tour.”

18. McDermott et al., "International Food Advertising, Pester Power and its Effects," 514-5.

19. Advertisement, Daily Mirror, July 22, 1964, 6.

20. "Businessman's Diary," Financial Times, December 16, 1963, 9; “Travel Equipment," Illustrated London News, January 11, 1964, 7.

21. “Advertising Standards Authority Set Up,” Financial Times, July 23, 1962, 7.

22. “Tighter advertising controls advocated," Financial Times, September 26, 1978, 8.

23. "Child ad scrutiny," Financial Times, November 9, 1978, 19.

24. "Lull in outside pressures to regulate the industry,"Financial Times, October 20, 1980, VIIIIX.

25. "Pirate Caroline 'on verge of profit," The Times, December 4, 1967, 1.

26. Peston, The British Economy, 127.

27. Carey, The Intellectuals and the Masses, 21.

28. Gardner, Faith and Doubt of John Betjeman, 183.

\section{Bibliography}

Carey, John. The Intellectuals and the Masses: Pride and Prejudice among the Literary Intelligentsia, 1880-1939. New York: St. Martin's Press, 1993. 
Frank, Thomas. The Conquest of Cool: Business Culture, Counter Culture, and the Rise of Hip Consumerism. Chicago and London: University of Chicago Press, $1997 .$.

Gardner, Kevin J. Faith and Doubt of John Betjeman: An Anthology of Betjeman's Religious Verse. London: Continuum, 2005.

Gwynn, Simon. “Heinz Marks 50 Years of ‘Beanz Meanz Heinz’ with Dining Bus Tour.” Campaign, October 13, 2017. Accessed November 18, 2020.

https://www.campaignlive.co.uk/article/heinz-marks-50-years-beanz-meanz-heinz-dining-bustour/1447347

“Henry John Heinz.” National Cyclopadia of American Biography 26, 294-5. New York: James T. White \& Company, 1937.

H.J. Heinz Company. Producers Manufacturers, Distributors: Pure Food Products: 57 Varieties. Pittsburgh: The Company, 1910.

Laird, Pamela Walker. Advertising Progress: American Business and the Rise of Consumer Marketing. Baltimore and London: Johns Hopkins University Press, 1998.

Levenstein, Harvey A. Revolution at the Table: The Transformation of the American Diet. New York: Oxford University Press, 1988.

McDermott, Laura, Terry O’Sullivan, Martine Stead, and Gerard Hastings. “International Food Advertising, Pester Power and Its Effects.” International Journal of Advertising 25, no. 4 (2006): 513-39.

Nevett, T. R. Advertising in Britain: A History. London: Heinemann, 1982, 7-9.

Peston, Maurice. The British Economy: An Elementary Macroeconomic Perspective. Oxford: Philip Allan, 1982.

Schwarzkopf, Stefan. "From Fordist to Creative Economies: The De-Americanisation of European Advertising Cultures Since the 1960s." European Review of History 20, no. 5 (2013): 859-79.

Segrave, Kerry. Endorsements in Advertising: A Social History. Jefferson, North Carolina and London: McFarland \& Company, Inc, 2005. 
Street, Seán. Crossing the Ether: British Public Service Radio and Commercial Competition, 1922-1945. Eastleigh: John Libbey, 2006.

“The H.J. Heinz Company.” The Successful American 2, no. 5 (1900): 42-9.

Wyckham, Robert G., Peter M. Banting, and Anthony K. P. Wensley. "The Language of Advertising: Who Controls Quality?” Journal of Business Ethics 3, no. 1 (1984): 47-53. 